\title{
Lojistik 4.0 Uygulamaları ve Lojistik Firmalarının Bakış AçıSI
}

\author{
BİHTER KARAGÖZ* \\ bihterkaragoz@arel.edu.tr \\ ORCID ID: 0000-0002-3966-1901
}

\author{
HANDE BEGÜM BUMIN DOYDUK** \\ hande.doyduk@altınbas.edu.tr \\ ORCID ID: 0000-0002-2917-2020
}

Öz: Teknoloji yoğun sektörlerden biri olan lojistikte faaliyet gösteren işletmeler, hayatlarını sürdürebilmek ve rekabet avantajı elde edebilmek için birçok farkh teknoloji kullanmaktadır. Günümüz rekabetçi ürün ve hizmetleri için lojistik 4.0 uygulamaları, işletmelerin iş yapma şekillerini hızla değiştirmektedir. Çalışmada Türkiye'de lojistik hizmet sunan işletmelerin lojistik 4.0’a bakış açıları ve uygulama düzeyleri belirlenmeye çalışılmıştır. Bu amaçla on adet lojistik hizmet sunan işletmeye derinlemesine mülakat yöntemi ile lojistik 4.0 kavramı ve uygulamaları sorulmuş olup, bu uygulamaların işletmeleri nasıl etkilediği belirlenmeye çalışılmıştır. Buradan hareketle sektörün lojistik 4.0 uygulamalarına ilişkin bir SWOT (GZFT - Güçlü ve Zayıf Yönler, Fırsatlar ve Tehditler) analizi yapılmıştır. Lojistik 4.0 uygulamalarına sahip olsun ya da olmasın işletmeler bu uygulamaların önemini anlamış bulunmaktalar. Araştırma sonucu, bu uygulamaların ülkemiz için giderek önem kazanacağını ortaya koymaktadır.

Anahtar Kelimeler: Endüstri 4.0, Lojistik 4.0, Lojistik.

\section{Giriş̧}

Küreselleşen dünya ve artan rekabet ortamı, teknolojide yaşanan gelişmeler, hızla değişen müşteri istek ve ihtiyaçları işletmeleri sürekli yenilik arayışına ve değişime yöneltmektedir. Bu yenilik ve değişimlerden en çok etkilenecek olan sektörlerden biri de lojistik sektörüdür. Günümüzde endüstri 4.0 uygulamaları lojistik sektöründeki firmalara değişimi zorunlu hale getirmektedir. Dördüncü Sanayi Devriminin bir parçası olarak lojistik 4.0’a doğru uzanan yol, yeni iş modellerine olanak sağlamakta olup anında bilgi alışverişi, otomatik çözümler ve gerçek zamanlı büyük veri analizi, lojistik 4.0’ın yeni iş modellerine olanak tanıyan özellikleri arasında yer almaktadır

Bu bağlamda çalışmanın ana amaçlarını (1) lojistik, lojistik 4.0 ve endüstri 4.0

\footnotetext{
* Dr. Öğr. Üyesi, İstanbul Arel Üniversitesi, Uygulamalı Bilimler Yüksekokulu, Uluslararası Taşımacılık ve Lojistik Bölümü.

** Dr. Öğr. Üyesi, Altınbaş Üniversitesi, İşletme Fakültesi, Uluslararası Ticaret Bölümü.

1 Jan Ola Strandhagen, Logan Reed Vallandingham, Giuseppe Fragapane, Jo Wessel Strandhagen, Aili Biriita Hætta Stangeland ve Nakul Sharma,"Logistics 4.0 and Emerging Sustainable Business Models", Advances in Manufacturing,(2017), s.359.

Gönderim 16 Ocak 2019

Düzeltilmiş gönderim 19 Mart 2019

www.insanveinsan.org e-ISSN: 2148-7537

Kabul 5 Eylül 2019 
literatürü olmak üzere kısa bir literatür değerlendirmesi yapmak; (2) lojistik firmalarının, lojistik 4.0 uygulamalarına bakış açılarını belirlemek; (3) sektörün, lojistik 4.0 uygulamalarına ilişkin bir SWOT analizini ortaya koymak; (4) lojistik hizmet sunan işletmelere yönelik hazırlanan anket çalışmasıyla araştırma sorularını test etmek; (5) araştırma bulgularının teorik ve pratik katkıları tartışılarak sonraki çalışmalara yönelik öneriler sunmak oluşturmaktadır. Ayrıca lojistik 4.0 ile ilgili çalışmaların henüz kısıtlı sayıda olması sebebi ile çalışmanın literatüre bu yönde bir katkı sağlaması da amaçlanmaktadır.

\section{Literatür İncelemesi}

\section{Lojistik}

Lojistik; 1990’lı yıllardan itibaren yaygınlaşmaya başlamış bir kavram olmasına karşın kökleri çok daha eski bir geçmişe uzanmaktadır².M.Ö. 500 gibi erken bir dönemde, Savaş Sanatı adlı metninde Sun TzuWu lojistik fonksiyonlarından ve bunların strateji ve taktik ile ilişkisinden bahsetmektedir ${ }^{3}$. Lojistik kelimesi ilk olarak ordu ile ilişkilendirilmiş ve 1905 yılında Albay Baker, "Orduların intikali ve tedariki ile ilgili Savaş Sanatı'nın bu dalına lojistik denmektedir” diye yazmıştır. II. Dünya Savaşı sonrasında ve özellikle 1950'lerle 1960'ların başlarında ayrı bir iş disiplini olarak ortaya çıkan lojistik;1980'lerden sonraçok sayıda teknolojik ve çevresel değişimlerden geçmiş olup, tüm bu değişiklikler sayesinde hem müşterilere hem de firmalara etkinlik, verimlilik ve/veya hizmet farklılaşması yönünde değer katmaya devam etmektedir.

Lojistik yönetimi; tedarik zinciri yönetiminin bir parçası olup müşterilerin ihtiyaçlarını karşılamak amacıyla, çıkış noktası ile tüketim noktası arasında malların, hizmetlerin ve ilgili bilgilerin etkili ve verimli bir şekilde ileri-geri akışının ve depolanmasının planlanması, uygulanması ve denetlenmesidir ${ }^{5}$. Yoğun rekabet ortamında birçok işletme için, lojistik kapasitenin ve yeteneklerin rekabet avantajı elde etmek üzere stratejik bir şekilde kullanımının önemi artmaktadır.

Günümüzde küresel iş dünyasındaki çeşitliliğin artmasıyla lojistik, birden çok ülkeyi içine alan daha uzun hatların etkin ve etkili yönetimi için zorlu bir alan olarak görülmekte ve bu görevi yerine getirmek için etkili bir bilgi işleme sistemine sahip olmak çok önemli hale gelmiştir'́ . Sürekli değişen teknolojik ve ilişkisel seçeneklere

\footnotetext{
2 John Mangan ve Chandra Lalwani, Global Logistics and Supply Chain Management, West Sussex, England: John Wiley\&Sons, Chichester, (2008), p.4.

3 Kent N. Gourdin, Global Logistics Management: A Competitive Advantage for the New Millenium, Oxford, United Kingdom: Blackwell Publishers, 2001, s.1.

4 James C. Johnson ve Donald F. Wood, Contemporary Logistics, New Jersey: Prentice Hall Inc, 1996, s. 4.

5 "Supply Chain Management Definitions and Glossary", CSCMP, Council of Supply Chain Management Professionals, Erişim 14 Mart 2018, https://cscmp.org/CSCMP/Educate/SCM_Definitions_and_Glossary_of_ Terms/CSCMP/Educate/SCM_Definitions_and_Glossary_of_Terms.aspx?hkey=60879588-f65f-4ab5-8c4b6878815 ef921.

6 Gürkan Öztürk, Ali Özkazanç ve Oğuzhan Kalabak, Lojistikte Teknoloji Kullanımı, ed., Gürkan Öztürk, Anadolu
} 
sahip küresel piyasa, firmaları yenilik yapmak üzere yeni yollar bulmaya sevk etmektedir. Sauvage zaman baskısı altındaki oldukça rekabetçi işlerde, teknolojik girişimlerin, lojistik hizmetlerde farklılık yaratmak için kritik bir değişken ve çok önemli bir araç olduğuna dikkat çekmektedir ${ }^{7}$.

\section{Lojistik Sektöründe Değişimler}

Son yıllarda, işletmelerin faaliyet gösterdikleri koşullar değişim göstermiş ve bu değişim lojistik alanını da yakından etkilemiştir. Grant'ın ${ }^{8} 1990$ 'larda yayınlanmış olan lojistiğin gelecekteki ihtiyaçları ve sorunlarına yönelik önceki çalışmaları incelemek amacıyla gerçekleştirdiği araştırma sonucuna göre; sanal lojistik veya e-ticaret dahil bilgi teknolojileri, entegre tedarik zinciri ve TZY ile müşteri hizmetleri olmak üzere yalnızca üç konu on kereden fazla ele alınmıştır.

Lojistik eğilimleri Bán tarafından 7 başlık altında özetlenmiştir9: (1) Strateji: İşletmelerde lojistiğin yerinin değişmesi, - Risk faktörlerinin artmasının kabulü, İşletme hedeflerinin sıralamasının değişimi, - Süreç kalitesi yönelimi; (2) Maliyet: Maliyetlerde azalma, Yalın lojistik ve JIT anlayışını geliştirme, Tasarrufta bulunma, Faaliyetlerin merkezileştirilmesi, - Artan enerji maliyetleri; (3) Şirket İşbirlikleri: - Diş kaynak, - Pazar konsolidasyonu, - Yerel, bölgesel ve küresel bazda standardizasyon, - Ortaklıklar ve stratejik ittifaklar; (4) Küreselleşme: - Küreselleşmenin artan etkisi, Küresel lojistik sistemlerin gelişimi, - Standardizasyona ilgi, - Konteyner lojistiği; (5) İnsan Kaynakları: - Nitelikli uzman eleman ihtiyacı, -Küresel iletişim ve know-how paylaşımı, Artan sosyal maliyetler, - Offshoring; (6) Teknoloji: - JIT, - Hızlı Yanıt, Etkin müşteri yanıtı, - Çapraz sevkiyat, - EDI, - RFID; (7) Çevre: - Yeşil lojistik, - Ters lojistik, - Çevresel süreçler, üretim ve hizmetler, - yaşam çevrim sürecine adaptasyon.

Zelevwski vd. ${ }^{10}$ çalışmalarında; 2020 yılına kadar lojistikte gerçekleştirilmesi beklenen teknolojik eğilimleri 10 madde altında toplamıştır: (1) Telematik uygulaması, (2) Bilgisayarlaştırma, yani; Lojistik sistemlerin bilgi ve iletişim teknolojisine daha derin nüfuz etmesi, (3) Simülasyon model ve yöntemlerinin uygulanması (lojistikalanında), (4) Sera gazı emisyonlarının azaltılması için trafik bilgi sistemleri, (5) IT sistemleri aracılığıyla ağ oluşturma ve entegrasyon, (6) Gerçek zamanlı rota yönetimine trafik bilgi sistemleri, (7) Taşımacılık bilgi sistemlerinin gerçek zamanlı kapasitesi, (8) GPS sisteminin uygulanması, (9) Nakliye hizmetleri için elektronik pazar yerleri (Nakliye borsaları), (10) Mobil programlamanın uygulanması.

\footnotetext{
Üniversitesi Yayın No: 2155, Açıöğretim Fakültesi Yayın No: 1183, Eskişehir, 2013, s.10.

7 Thierry Sauvage, “The Relationship Between Technology and Logistics Third冈Party Providers”, International Journal of Physical Distribution \& Logistics Management, 33/3 (2003), s.236.

8 David B. Grant, “Trends in Logistics and Supply Chain Management: A Focus on Risk", Journal of Supply Chain Management, 8/2 (2014), s.2.

9 Martin Podaril ve Soňa Rusnakova, "Trends and Development in Logistics”, LOGI Scientific Journal on Transport and Logistics, 5/2 (2014), s.51.

10 Stephan Zelewski, Alessa Münchow-Küsterand Rene Föhring. "Logistics Trends 2020: A National Delphi Study Concerning the German Logistics Sector", Next Generation Supply Chains Trends and Opportunities, ed., Kersten, W., Blecker, T., Ringle, C. M., HICL, Hamburg, 2014.
} 
DHL Trend Research 2014 giderek yerleşmesi beklenen teknolojik eğilimlerin bazılarını "bulut lojistik, supergrid lojistik, ileriye yönelik lojistik, çoklu-kanal lojistik ve katkılı üretim (3B Baskı)” olarak tespit etmiştir ve bu rapora göre, bu eğilimlerin lojistik endüstrisini beş yıl kadar kısa bir süre içinde etkileyeceği beklenmektedir ${ }^{11}$. Benzer şekilde Angeleanu bu beş yeni teknolojik eğilimi incelemiş ve yine bu yeni eğilimlerin önümüzdeki beş yıl içinde lojistik sektörünü etkilemesi beklendiği sonucuna ulaşmıştır ${ }^{12}$.

\section{Endüstri 4.0 ve Lojistik}

Endüstri 4.0 kavramı; rekabetçiliğin sürdürülmesi açısından önemli bir strateji olarak görülmekle beraber, rekabetçi ürün ve hizmetlerin yanı sıra idari açıdan güçlü ve esnek lojistik ve üretim sistemlerinin tasarım ve uygulamasını da kapsamaktadır ${ }^{13}$. Endüstri 4.0'daki gelişmeler lojistiği ciddi bir şekilde etkileyerek lojistik 4.0’ın doğmasına yol açmış; bu sayede sürdürebilirlik, verimlilik, müşterilere cevap verme yeteneği ve daha iyi izlenebilirlik gibi lojistiğin farklı noktalarının iyileştirilmesinin yanı sıra işin asli unsurları da bundan etkilenir hale gelmiştir ${ }^{14}$. Siparişin verildiği andan başlayarak ürün ömrü sonuna kadarki tüm adımlarda şeffaflı̆̆ı artırmak için tedarikçi, imalatçı ve müşteriler arasında iyi bir işbirliğinin tesis edilmesi çok önemli olduğundan, endüstri 4.0'ın tedarik zinciri üzerindeki etkisini bir bütün olarak analiz etmek şarttır ${ }^{15}$. Nesnelerin interneti teknolojisi ulaşımda ve lojistik sektöründe büyük yeniliklere yol açmakta ve üretimden başlayıp son ürünün müşteriye teslimine kadar tedarik zinciri (TZ) ve lojistiğin tüm aşamalarında pozitif anlamda bir katkıda bulunmaktadır ${ }^{16}$.

11 Andra Angeleanu, "New Technology Trends and Their Transformative Impact on Logistics and Supply Chain Processes", International Journal of Economic Practices and Theories, 5/5 (2015), s.413.

12 Angeleanu, "New Technology Trends and Their Transformative Impact on Logistics and Supply Chain Processes", s.418.

13 Frank Rennung, Caius Tudor Luminosua ve Anca Draghici, "Service Provision in the Framework of Industry 4.0”, Procedia - Social and Behavioral Sciences, 221 (2016), s.373.

14 Jan Ola Strandhagen, Logan Reed Vallandingham, Giuseppe Fragapane, Jo Wessel Strandhagen, Aili Biriita Hætta Stangeland ve Nakul Sharma, "Logistics 4.0 and Emerging Sustainable Business Models", Advances in Manufacturing,(2017), s.359.

15 Benny Tjahjono vd. "What does Industry 4.0 Mean to Supply Chain?” (Manufacturing Engineering Society International Conference, MESIC 2017, Vigo (Pontevedra), Spain, June 28-30, 2017).

16 Sema Kayapınar, “Endüstri 4.0’ın Dünü, Bugünü ve Yarını: Lojistik Sektörü”, (International Regional Development Conference, Munzur University, Tunceli, September 21-23, 2017). 


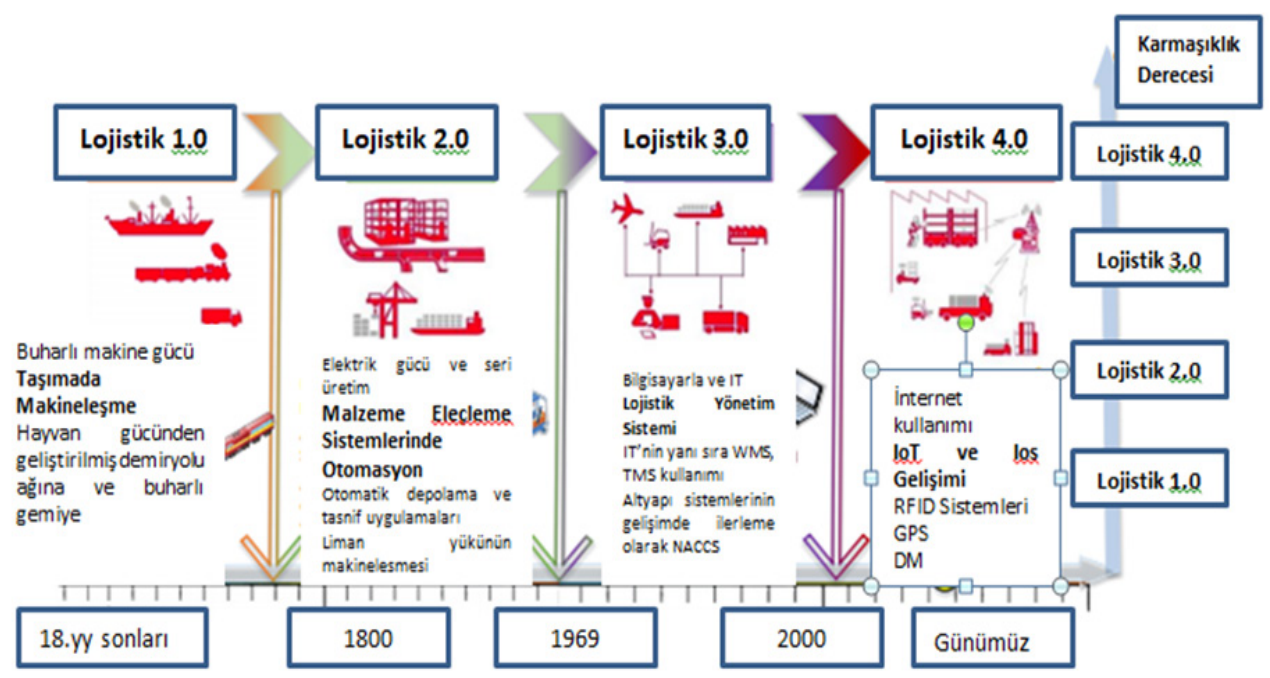

Şekil 1 Lojistiğin Gelişimi Laura Domingo Galindo, "The Challenges of Logistics 4.0 for the Supply Chain Management and the Information Technology", Master Thesis, NorwegianUniversity of Science and Technology, 2016, p. 25.

Şekil 1'i ayrıntılı bir şekilde açıklamak gerekirse ${ }^{17}$ : sektörde algılanan ilk değişiklik o kadar anidir ki devrim olarak nitelendirilmektedir. $\mathrm{Bu}$ değişim manuel işten makineleşmeye geçişti. Bu andan itibaren kırsal hayat, el aletleri ve hayvan gücü ile çalışmaktan endüstriyel üretim makinelerine, mal ve insan taşımacılığına kadar bir sanayileşme yaşantısına dönüştü. Bu nedenle bu dönem, lojistik için "taşımada makineleşme" anlamına gelmektedir. Tedarik zinciri yönetimi, ağların bulunmadığ 1 ve işletmenin daha yakın konumdaki tedarikçiler ile birlikte olma eğiliminde olduğu yerel bir operasyondu. İşletmelerin çoğu bireysel sahipler ya da ortaklar tarafından yönetiliyordu; bunların bir kısmı, çoğu kez operasyonların sorumluluğunda genellikle az bir paya sahipti. Depolar, malzemelerin ya da tamamlanmış ürünlerin konulduğu basit odalar şeklindeydi (Lojistik 1.0). İkinci değişim periyodu, teknoloji açısından bir devrimden ziyade bir evrim olarak kabul edilmektedir. Lojistik alanındaki gelişmelere ilişkin olarak, 1960'lardan itibaren "malzeme elleçlemede otomasyon" görülmektedir. Tedarik zinciri yönetimi, birden fazla tedarikçinin dikkate alındığ ve tedarik ilişkilerinin sürekli olduğu bir global düzen haline geldi. Mekanik veya mühendislik alanında uzmanlık gerektiren yeni sanayi türleri ile işletmeler, gerekli uzmanlığa sahip profesyonel yöneticileri işe almaya başladı. Depo otomatik olmaya ve bir depodaki bir raf boyunca bir konteynerin bir kabın içinde depolandı̆̆ 1 veya raftan alınacağı şekilde hareket ettirilmesiyle çalıştırılmaya başladı (Lojistik 2.0). Endüstriyel evrim, bilgisayarların üretime girmesiyle gerçekleşti. Lojistik ile ilgili olarak "lojistik yönetim sistemi” geliştirildi. Günümüzde sıkça kullanılan WMS (depo yönetim sistemleri), TMS (taşıma yönetim sistemleri) ve bilgi teknoloji sistemleri önemli yazılımların başlangıcı olmakla beraber bütün bunlar lojistik

17 Laura Domingo Galindo, "The Challenges of Logistics 4.0 for the Supply Chain Management and the Information Technology”, Master Thesis, Norwegian University of Science and Technology, 2016, s.25-32. 
süreçleri yönetmek ve kontrol etmek için bilgisayarların kullanımıyla önemli bir ilerleme kaydetmiştir. Tedarik zinciri yönetimi tamamen globaldir, küresel pazardaki en iyi tedarikçi işe alınır ve daha kısa ilişkiler kurulur (Lojistik 3.0). Üretimde bu yeni paradigma kayması, gerçek zamanlı olarak birbirleriyle makineler ve insanlar arasındaki iletişimi sağlayan internet kullanımı ve "akıllı ürünler ve akıllı servisler" olarak bilinen şeyin kullanımı ve aynı zamanda fabrikalarda gelişmiş dijitalleştirmenin bir sonucudur. Bu geleceğin "akıllı fabrikası", üretim süreçlerinde yer alan tüm unsurları birbirine bağlamayı ve uyumluluk, birbirine bağlılık, verimlilik ve ergonomi kavramlarının uygulanmasını mümkün kılacaktır. Otomatik depolar ve otomatik sıralama gibi lojistik donanımlar zaten yaygındı, ancak yayılma aralığı sınırlıydı, ancak şimdi ilgi konusu paketin şekli ve karakteristiğine göre özel bir sistem haline geldi. Bu nedenle amaç, elleçleme işçiliğinden ve taşımacılıktan zaman tasarrufu sağlayan yeni teknolojiyi tanıtmaktır (Lojistik 4.0).

\section{Lojistik 4.0}

Lojistik 4.0 çoğu çalışmada akıllı lojistik olarak tanımlanmaktadır ${ }^{18}{ }^{19}$ ve lojistik ile bilgi lojistiği açısından daha verimli bir organizasyon adına önemli bir yaklaşımdır20 Ürün yaşam döngüsü boyunca ve ürün yaşam döngüleri arasındaki malzeme akışı, akıllı lojistik ile gerçekleştirilecektir ${ }^{21}$. Akıllı lojistik; akıllı ürünlerin yanı sıra akıllı hizmetlerin de lojistik içerisine dâhil edilmesine olanak tanımaktadır ${ }^{22}$.Akıllı lojistik veya lojistik 4.0 gibi teknik gelişmeler, kısmen yeni iş modelleri için somut çözümlerin hayata geçirilmesinde gerekli koşulları yaratmaktadır ${ }^{23}$.

Lojistik 4.0; üst düzey bir otomasyon seviyesine ulaşabilmek amacıyla internet (nesnelerin interneti) üzerinden toplanıp paylaşılan ilgili bilgilerin işlendiği veritabanlarına ve yazılımlara sahip, akıllı sensörlerle (RFID sistemleriyle) desteklenen lojistik ve tedarik zinciri süreçleri olarak özetlenebilecek geniş kapsamlı bir terim olup, tüm makinelerin birbirleriyle ve insanlarla iletişim içinde olduğu bir lojistik ağını ifade etmektedir ${ }^{24}$. Barreto vd. ise lojistik 4.0', ileri seviye bir otomasyon sağlamak amacıyla nesnelerin interneti tabanlı sistemlerle toplanıp paylaşılan ilgili bilgilerin işlendiği veri tabanlarına ve yazılımlara sahip akıllı sistemlerle desteklenmesi gereken bir gelen ve giden lojistik optimizasyonu olarak özetlemiştir ${ }^{25}$.

18 Galindo, "The Challenges of Logistics 4.0 for the Supply Chain Management and the Information Technology”, s.1-96.

19 Mirosla Fusko, Patrik Grznár ve Marcel Jančo, "Employees for New Production Systems" (Industrial Engineering Invention For Enterprise Inv Ent, Szczyrk, PL, June 19-21, 2017).

20 Martin Kirch, Olaf Poenicke ve Klaus Richter, "RFID in Logistics and Production - Applications, Research and Visions for Smart Logistics Zones", Procedia Engineering, 2017, 178, s.526.

21 Tim Stock ve Guenther Seliger, “Opportunities of Sustainable Manufacturing in Industry 4.0”, (Procedia CIRP, 2016)

22 Dieter Uckelmann, “A Definition Approach to Smart Logistics”, Erişim 2 Nisan,2018, https://rusmart.e-werest. org/2008/uckelmann.pdf

23 Fusko vd.,"Employees for New Production Systems”, s.48.

24 Galindo, "The Challenges of Logistics 4.0 for the Supply Chain Management and the Information Technology", s.20.

25 Luis Barreto, Antonio Amaraland ve Teresa Pereira. "Industry 4.0 Implications in Logistics: an Overview" 
Nesnelerin interneti ise; lojistik işletmeleri, müşterileri ve son tüketiciler için geniş kapsamlı getiriler vaat etmektedir ${ }^{26}$.

Çileklii ${ }^{27}$ çalışmasında sanayi 4.0 teknolojilerininlojistik sektöründekiuygulamalarının faydalarını maddeler halinde sıralanmaktadır: (1) Lojistikte, depo operasyonlarında, sipariş seçmede/toplamada süreç ve işgücü verimliliğinin artması, çarpışma ve kaza olmadan güvenli, kesintisiz hizmet verilmesi, risklerin ve ürün kayıplarının azalması,

(2) Yedek parça üretimi ve bazı lojistik hizmetlerinde taşıma ve stok maliyetleri ile teslimat süresi ve karbon salınımlarının azalması, yakıt tasarrufu ve kaynak verimliliği,

(3) Kapasite planlaması, varlıkların optimize kullanımı, yükleme sırası ve araç rota optimizasyonu, tam zamanlı çizelgeleme ve anlık varış zamanı tahmini,

(4) Teslimat lokasyonu kümeleme, her bir sipariş için zaman tercihli teslimat planlaması, tahmini gecikme uyarıları, optimize tur planlaması, taşıma mesafelerinin ve maliyetlerinin düşmesi, bekleme sürelerinin ve boş gezintilerin azalması,

(5) Lojistik operasyonların şeffaflığının, izlenebilirliğinin ve güvenilirliğinin artması, malların hırsızlığa ve hasarlara karşı korunması.

Lojistikte süreç verimliliği önemli bir göstergedir ve bu nedenle tüm lojistik 4.0 uygulamaları bir şekilde verimliliği artırmaya gayret etmektedir ${ }^{28}$.Szymańska vd. çalışmasında; lojistik 4.0'ın avantajlarını: (1) insan kaynaklarında tasarruf, (2) lojistik fonksiyonların bilgi parçalarına bağlanmasının yüksek standardizasyonu ve (3) lojistik işletmelerin en yeni teknolojileri kullanımı ve dezavantajlarını ise: (1) yüksek yatırım maliyetleri ve (2) IT tedarik ağı bulundurma gerekliliği olarak belirtmiştir ${ }^{29}$.

Lojistik 4.0; tedarik zinciri üyelerinin verimliliğini ve performansını arttırmayı amaçlamaktadır ${ }^{30}$. Barreto vd.'ne göre etkin ve güçlü bir lojistik 4.0: (1) kaynak planlama, (2) depo yönetim sistemleri, (3) taşımacılık yönetim sistemleri, (4) akıllı taşımacılık sistemleri ve (5) bilgi güvenliği gibi teknolojilere dayanmalı ve bu teknolojilerden yararlanmalıdır ${ }^{31}$.

\footnotetext{
(Manufacturing Engineering Society International Conference, Vigo (Pontevedra), Spain, June 28-30, 2017). 26 Joanna Oleśków-Szłapkaand PiotrLubińsk. "New Technology Trendsand Solutions in Logistics and Their Impact on Processes", (3rd International Conference on Social Science, Shanghai, China, December 9-11, 2016, s.412).

27 Sadık Çilekli. "Sanayi 4.0’ın Lojistik Sektörüne Etkileri”, Anahtar Dergisi, T.C. Bilim Sanayi ve Teknoloji Bakanlığı, 352 (2018), s.45-50.

28 Daan Horenberg, "Applications with in Logistics 4.0 A Research Conducted on the Visions of 3PL Service Providers", Thesis, University of Twente, 2017.

29 Olga Szymańska, Michał Adamczak ve Piotr Cyplik, "Logistics 4.0 - A New Paradigmor Set of Known Solutions?", Research in Logistics and Production, Poznan University of Technology Publishing House, Poznan, 7/4 (2017), s.303.

30 Olga Szymańska, Michał Adamczak ve Piotr Cyplik. "Logistics 4.0 - A New Paradigmor Set of Known Solutions?", Research in Logistics and Production, 7/4 (2017), s.303.

31 Barreto vd.,"Industry 4.0 Implications in Logistics: an Overview", s.1248.
} 
2014 yılında Forrester Consulting tarafından Zebra Technologies adına yapılan araştırma sonuçlarına göre ${ }^{32}$ : (1) Lojistik ve ulaştırma sektöründeki şirketlerin yaklaşı \%90'ı, halihazırda nesnelerin interneti çözümlerini hayata geçirmiş veya önümüzdeki yıl içinde hayata geçirmiş olacaktır, (2) Katılımcıların yarısından fazlası nesnelerin interneti sayesinde tedarik zincirinin daha çok gelişeceğini düşünmektedir, (3) Katılımcıların \%40’ı nesnelerin internet'i sayesinde firmaların güvenlik düzeyi ve maliyet-etkinliğinin artacağını düşünmektedir, (4) Nesnelerin interneti uygulanmasındaki başlıca teknolojilerin wi-fi bağlantısı, güvenlik sensörleri ve NFC iletişimi (Yakın Alan İletişimleri) olduğu varsayılmaktadır, (5) Katılımcıların yaklaşı \%40'1, nesnelerin interneti çözümlerinin uygulanmasının önündeki en büyük engel olarak bilgi güvenliği ve gizliliğe ilişkin kaygılarını dile getirmiştir, (6) Katılımcıların \%38'i, bu çözümlerin son derece karmaşık olduğunu ve dolayısıyla uygulama riskinin yüksek olduğunu ifade etmiştir.

\section{Yöntem}

Lojistik hizmet sunan işletmelerin lojistik 4.0'a bakış açıları ve uygulama düzeylerinin belirlenmesine yönelik yapılan bu araştırmada nitel araştırma yöntemi kullanılmıştır. Araştırmanın küçük bir örneklem üzerinde gerçekleşecek olması sebebi ile bu yöntem tercih edilmiştir. Bu durumda elde edilen verilerin evrene genellenebilirliği söz konusu olmadığından istatistiksel temsil edilebilirlik yerine daha bütünsel, derinlemesine ve bağlamında anlaşılmasına ilişkin yönelim söz konusu olmuştur ${ }^{33}$. Konu ile ilgili esnek, zengin ve olabildiğince detaylı bir şekilde veri toplanmasına imkân tanımasi ${ }^{34}$ sebebi ile de nitel araştırma yöntemlerinden derinlemesine görüşme tekniği tercih edilmiştir.

$\mathrm{Bu}$ amaçlar doğrultusunda Ocak-Nisan 2018 tarihleri arasında 10 adet lojistik firmasının orta düzey yöneticisine daha önceden oluşturulan mülakat formu vasıtası ile sorular yöneltilmiştir. Nitel araştırmalarda örneklem sayısı tekrar durumuyla belirlenir. Aynı bilgilerin farklı örneklerde tekrarlanması bilginin doyuma ulaşma noktası olarak görülür ${ }^{35}$. Hazırlanan mülakat formu 3 ana bölümden meydana gelmiş olup; birinci bölümü lojistik firmasına ait genel bilgileri içeren kapalı uçlu sorulardan; ikinci ve üçüncü bölümü ise açık uçlu-yarı yapılandırılmış- sorulardan oluşmaktadır.

\section{Araştırma Bulguları}

Görüşmenin ilk bölümünde araştırmaya katılan işletmelere ait genel bilgiler -

32 Krzysztof Witkowski. "Internet of Things, Big Data, Industry 4.0 - Innovative Solutions in Logistics and Supply Chains Management”, Procedia Engineering, 2017, s.767.

33 Oğuz Çetin. “Nitel Bir Araştırma Tekniği: Görüşme”, Erişim 12 Mart, 2018, https://oguzcetin.gen.tr/nitel-birarastirma-teknigi-gorusme.html.

34 Hasan Hüseyin Tekin. "Nitel Araştırma Yönteminin Bir Veri Toplama Tekniği Olarak Derinlemesine Görüşme”, İstanbul Üniversitesi Sosyoloji Dergisi, 13/3 (2006), s.104.

${ }^{35}$ Morgan, David ve Robert Morgan. "Single-Case Research Methods For The Behavioral And Health Sciences", SAGE Publications, 2008. 
çalışan sayısı, hizmet süresi, hizmet düzeyi ve lojistik 4.0 uygulamalarının varlığısorulmuştur. Bu bağlamda, Tablo l'de araştırmaya katılan işletmelere ait genel bilgiler yer almaktadır.

Tablo 1 Araştırmaya Katılan İşletmeler Ait Genel Bilgiler

\begin{tabular}{|l|c|l|l|l|}
\hline & $\begin{array}{l}\text { Lojistik 4.0 } \\
\text { Uygulaması }\end{array}$ & Çalışan Sayısı & Hizmet Süresi & Hizmet Düzeyi \\
\hline Lojistik İşletme 1 & $\checkmark$ & $>500$ & $29 \mathrm{yll}$ & Uluslararası \\
\hline Lojistik İşletme 2 & - & $>200$ & $42 \mathrm{yll}$ & Uluslararası \\
\hline Lojistik İşletme 3 & $\checkmark$ & $>7000$ & $28 \mathrm{yll}$ & Uluslararası \\
\hline Lojistik İşletme 4 & - & $<100$ & $23 \mathrm{yll}$ & Ulusal \\
\hline Lojistik İşletme 5 & $\checkmark$ & $>400$ & $38 \mathrm{yll}$ & Uluslararası \\
\hline Lojistik İşletme 6 & $\checkmark$ & $>1400$ & $29 \mathrm{yll}$ & Uluslararası \\
\hline Lojistik İşletme 7 & $\checkmark$ & $>3000$ & 19 yll & Uluslararası \\
\hline Lojistik İşletme 8 & $\checkmark$ & $>700$ & $72 \mathrm{yll}$ & Uluslararası \\
\hline Lojistik İşletme 9 & $\checkmark$ & $<100$ & 6 yıl & Uluslararası \\
\hline $\begin{array}{l}\text { Lojistik Işletme } \\
\text { 10 }\end{array}$ & $\checkmark$ & $<100$ & 21 yll & Uluslararası \\
\hline
\end{tabular}

Görüşmenin ikinci bölümünde ilk olarak işletmelere lojistik 4.0 uygulamaları olup olmadığı yönünde soru yöneltilmiştir. Çalışmaya katılan 10 işletmeden 8 tanesilojistik 4.0 uygulamasına sahip olduğunu belirtmiştir. Sonrasında mülakat formunda, açı uçlu sorulara yer verilmiştir. Bu doğrultuda çalışmaya katılan işletmelerin başlıca lojistik4.0 uygulamalarının; nesnelerin interneti, sensörler, yapay zeka, siber güvenlik ve bulut bilişimi olduğu görülmektedir. Bu işletmeler; 4.0 gelişmeleri ile nesnelerin algılanabilir hale getirilmesiyle elde edilen verileri anlamlı bilgilere dönüştürmekte ve sensörlerden aldığı verileri kendi kendine karar verebilen teknolojilere yönelik çalışmalar yapmaktalar.

Çalışmaya katılan işletmeler yoğun olarak lojistik 4.0 uygulamalarını nakliye ve depolamada kullanmakta oldukları ortaya çıkmışıı. Bu sayede işletmeler bir takım avantajlar elde ettiklerini belirtmiştir: (1) hizmet çeşitliliği, (2) müssteri memnuniyet seviyesinde artış, (3) maliyet avantajı, (4) daha esnek faaliyetler, (5) hızlı cevap, (6) en az hata oranı,(7) gerçek zamanlı bilgi akışı, (8) işlem hızında artış, (9) verimlilik ve (10) hizmet kalitesi. Ayrıca işletmeler bu uygulamalar ile, süreci eş zamanlı takip etme şansı yakalayabildiklerini de eklemiştir. Araştırmaya katılan yöneticiler, çalışanlarının ilk başta bu uygulamaları zor kabullendiklerini ama sonrasında işleyişten memnun olduklarını belirtmiştir.

Araştırma ile, bu yeni uygulamalarda bir diğer önemli konunun da veri güvenliği olduğu sonucuna ulaşılmıştır. İşletmelerin bu konuda birtakım çalışmaları mevcut olmakla beraber, yine güvenlik amaçlı olarak işletmelerin çoğu paylaşmak istememiştir. İki işletme ISO 27001 (Bilgi Güvenliği Yönetim Sistemi) kapsamında güvenlik önlemleri aldığını belirtmiştir. 
Çalışmaya katılan işletmelerden özellikle bir tanesi kendisini sektöründe endüstri 4.0'ın öncüsü olarak görüyor ve lojistik 4.0'ı ilkesi olarak benimsemiştir. Bu işletme teknolojik rekabette sunduğu hizmetlere örnek olarak; insan eli değmeden depolanan ve yine insan eli değmeden araçlara yüklenebilen giysi gruplarını vermiştir. Lojistik 4.0 uygulamalarına sahip 3 işletme de rakiplerinden iş yapış süreçlerinde ayrıldıklarını vurgulamıştır.

Görüşmenin üçüncü bölümünde, lojistik sektörünün endüstri 4.0 uygulamaları durum analizini tespit etmek amacıyla her 6 işletmeye de sorular yöneltilmiştir. Bu bağlamda sektörü bekleyen fırsatlar ve tehditler ile avantajlı ve dezavantajlı yönler belirlenmeye çalışılmış olup Tablo 2'de bu bilgilere yer verilmiştir.

Tablo 2 Lojistik 4.0 Uygulamaları Fırsat ve Tehditleri ile Güçlü ve Zayıf Yönleri

\begin{tabular}{|c|c|}
\hline Firsatlar & Tehditler \\
\hline $\begin{array}{ll}\text { - } & \text { İzlenebililirlik / Takip } \\
\text { - } & \text { Tam otomasyon } \\
\text { - } & \text { Hız } \\
\text { - } & \text { Eş zamanlı veri paylaşımı } \\
\text { - } & \text { Maliyet avantajı } \\
\text { - } & \text { Mal ve hizmet miktarında artış } \\
\text { - } & \text { Kontrol gücünde artış } \\
\text { - } & \text { Etkin iletişim sistemleri } \\
\text { - } & \text { Yurtdışı pazarlara entegrasyon } \\
\text { - } & \text { Blockchain uygulamaları }\end{array}$ & 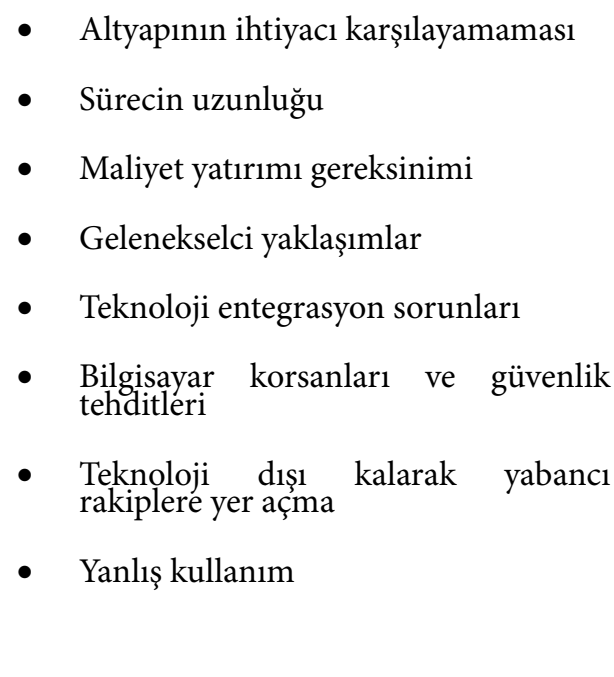 \\
\hline Güçlü Yönler & Zayıf Yönler \\
\hline $\begin{array}{ll}\text { - } & \text { Maliyetlerin azalması } \\
\text { - } & \text { Müşsteri sadakatı̧an verimliliği } \\
\text { - } & \text { Hizmet çeşitliliği } \\
\text { - } & \text { Hizmet kalitesi } \\
\text { - İş yapış şekillerinin değişmesi } \\
\text { - } \quad \text { Daha verimli işleyiş } \\
\text { - Katma değer zinciri } \\
\text { - Özellikle insan kaynaklı hataları }\end{array}$ & $\begin{array}{l}\text { - İstihdam üzerinde olumsuz etkisi } \\
\text { olacağına dair genel kanı } \\
\text { - } \quad \begin{array}{l}\text { Finansal, sektörel ve kamusal } \\
\text { platformların yetersizliği }\end{array} \\
\text { - Teşvik sisteminin yetersizliği } \\
\text { - Yatırım maliyeti } \\
\text { - İnternet bağlantılarının standart } \\
\text { olmaması }\end{array}$ \\
\hline
\end{tabular}


Araştırma sonuçlarına göre, lojistik 4.0 uygulamalarının insan kaynakları yönetimi açısından avantajı "etkin süreç ve performans yönetimi” olarak belirlenmiş olup; dezavantajlı yönü ise, "mavi yakalı ve düşük katma değer sağlayan beyaz yakalı istihdamı üzerinde olumsuz etki" ve özellikle çalışanların "bu uygulamaların insan kaynağına olan ihtiyacı azaltacağı” yönünde önyargılarından oluştuğu belirlenmiştir. Bununla beraberaraştırmaya katılan işletmeler, bilgi teknolojileri ile insan odaklı, bütün paydaşlarıyla katma değeri yüksek organizasyonlar oluşturmayı amaçlamakta olduklarını; bu doğrultuda da çalışanlarının teknolojik gelişmelere istekli olduğunu belirtmiştir.

Araştırma sonuçlarına göre, lojistik 4.0 uygulamalarının müşteri ilişkileri yönetimi açısından avantajları "artan müşteri ilişkileri-artan hizmet kalitesi” olarak belirlenmiş olup; bunu "değişen müşteri istek ve beklentilerini, müşterilere özel hizmetler geliştirerek, eş zamanlı çözümler oluşturularak” yakalanabileceğini belirtmişlerdir. Lojistik 4.0 uygulamalarının müşteri ilişkileri yönetimi açısından dezavantajları ise, "sektörler arasındaki entegrasyon farkı" olarak belirlenmiştir.

Lojistik 4.0 uygulamalarının bilgi paylaşımı/iletişim açısından avantajları; hızlı bilgi aktarımı ve gerçek zamanlı veri toplama, analiz etme ve raporlama sistemleri sayesinde etkin bilgi paylaşımı sağlama olarak 2 başlık altında toplanmıştır. Bununla beraber, bilgilerin doğrulanması ve bilgi güvenliğinin sağlanması üzerinde önemle durulması gereken konular halini aldığı görülmektedir.

Araştırmaya katılanlar, genel olarak işletmelerine ya da sektör geneline lojistik 4.0 uygulamalarının avantajlarını sıraladıklarında “yük, araç ve müşteri takibi” öncelikli olarak görülmektedir. Aynı şekilde lojistik 4.0 uygulamalarının dezavantajlarını genel olarak sıraladıklarında ise "bilgi güvenliği" öncelikli olarak görülmektedir. Çalışmada Lojistik İşletmesi 8 olarak adlandırılan işletme, 2017 yılında siber saldırıya uğradıklarını ve toplama, dağıtım, araç kullanma vb. sıkıntıları yaşadıklarını eklemiştir.

Çalışmaya katılan işletmeler sektörlerindeki rakipleri hakkında soruları yanıtsız bırakmış ve herhangi bir olumlu ya da olumsuz cevap vermemiştir. Çalışmada Lojistik İşletmesi 7 olarak adlandırılan işletme "lojistik 4.0'ın gelişmiş ülkelerde tam anlamıyla uygulandığını, Türkiyedeki işletmelerin lojistik 4.0’1 yeni gündeme getirdiğini ve bunun da ötesinde gelişmiş ülkelerde endüstri 5.0 ile ilgili çalışmaların ilerlediğini” eklemiştir.

\section{Sonuç}

Lojistik 4.0 uygulamalarına sahip olsun ya da olmasın işletmeler, bu uygulamaların yararlarını fark etmiş bulunmakta. Witkowskỉnin de belirttiği gibi nesnelerin interneti, endüstri 4.0 gibi en yeni çözümler müşterilerin ihtiyaçlarını karşılamak için fırsatlar yaratarak, lojistik ve tedarik zinciri yönetiminin iyileştirilmesine katkıda 
bulunmaktadır ${ }^{35}$. Yine Oleskow ve Lubıńsk’nin çalışmaları sonucuyla paralel olarak lojistik 4.0’nn gelişimi işletmeler içinde büyük değişiklikler yaratmakta ve lojistik işletmeleri lojistik 4.0 uygulamalarına yatırımlarını arttırmalıdır ${ }^{36}$.

Lojistik 4.0 uygulamalarını lojistik sektöründe inceleme amacıyla oluşturulan bu çalışmada, arzu edilen sonuçlara ulaşamadık. Türkiye'deki lojistik işletmeleri yeniliğe çok açık olmamakla beraber, teknoloji yatırımlarını büyük maliyet kalemi olarak görmekteler. Ayrıca lojistik 4.0 uygulamalarından, tüm lojistik süreç yerine özellikle yoğun olarak nakliye ve depolamada kullanmaktalar. Çalışmaya katılan bir işletmenin de belirttiği gibi, lojistik sektöründe mevcutta tam anlamıyla endüstri 4.0 uygulaması yapılmıyor ama AR-Ge çalışmaları devam ediyor. Gerek şu anki ülkemizdeki mevcut uygulamaların yetersizliği, gerekse bazı yöneticilerin çalışmaya katılımdaki isteksizlikleri çalışmanın sınırlarını belirledi. Çalışmada lojistik 4.0 uygulamalarına ilişkin güçlü zayıf yönler ile bu konudaki firsat ve tehditleri değerlendirmek bir diğer esas konuydu ve bu bağlamda yöneticilerin daha geniş ve derin bakış açılarına sahip olmaları gerekliliği sonucuna ulaşıldı. Araştırmaya katılan işletmelerin çoğunda kendilerine rakip görmedikleri belirlendi, hâlbuki faaliyet sahalarındaki dünya liderlerini belirlemeli ve bu yönde kendilerini geliştirmek için çalışmalar yapmalıdırlar.

$\mathrm{Bu}$ çalışma, günümüzde çok önemli bir konu olan lojistik 4.0 kavramını genel olarak incelemiştir. Lojistik 4.0 ile ilgili çalışmalar şu an için literatürde az olmakla beraber, son zamanlarda bu konu ile ilgili çalı̧̧malar giderek artmaktadır. Gelecekteki çalışmalar, bu konuyu daha zenginleştirecektir.

\section{Kaynakça}

Angeleanu Andra. "New Technology Trends and Their Transformative Impact on Logistics and Supply Chain Processes". International Journal of Economic Practices and Theories. 5/5 (2015): 413-419.

Barreto, Luis, Antonio Amaral ve Teresa Pereira. "Industry 4.0 Implications in Logistics: an Overview". Manufacturing Engineering Society International Conference. Vigo (Pontevedra), Spain. June 28-30, 2017.

CSCMP, Council of Supply Chain Management Professionals. "Supply Chain Management Definitions and Glossary". Erişim 14 Mart 2018. https://cscmp.org/ CSCMP/Educate/SCM_Definitions_and_Glossary_of_Terms/CSCMP/Educate/SCM_Definitions_and_Glossary_of_Terms.aspx?hkey=60879588-f65f-4ab58c4b-6878815ef921.

Çetin, Oğuz. "Nitel Bir Araştırma Tekniği: Görüşme". Erişim 12 Mart, 2018. https:// oguzcetin.gen.tr/nitel-bir-arastirma-teknigi-gorusme.html

35 Witkowski. "Internet of Things, Big Data, Industry 4.0 - Innovative Solutions in Logistics and Supply Chains Management", s.767.

36 Oleskow and Lubıńsk, "New Technology Trends and Solutions in Logistics and Their Impact on Processes". 
Çilekli, Sadık. "Sanayi 4.0'ın Lojistik Sektörüne Etkileri”. Anahtar Dergisi. T.C. Bilim Sanayi ve Teknoloji Bakanlığı. 352 (2018): 45-50.

Fusko, Mirosla, Patrik Grznár ve Marcel Jančo. “Employees for New Production Systems”. Industrial Engineering Invention For Enterprise Inv Ent. Szczyrk, PL. June 19-21, 2017.

Galindo, Laura Domingo. “The Challenges of Logistics 4.0 for the Supply Chain Management and the Information Technology". Master Thesis. Norwegian University of Science and Technology. 2016.

Gourdin Kent N. Global Logistics Management: A Competitive Advantage for the New Millenium. Oxford, United Kingdom: Blackwell Publishers. 2001.

Grant, David B., "Trends in Logistics and Supply Chain Management: A Focus on Risk". Journal of Supply Chain Management. 8/2 (2014):1-12.

Horenberg, Daan. "Applications With in Logistics 4.0 A Research Conducted on the Visions of 3PL Service Providers". Thesis, University of Twente. 2017.

Johnson, James C. ve Donald F.Wood. Contemporary Logistics. New Jersey: Prentice Hall Inc. 1996.

Kayapınar, Sema. “Endüstri 4.0’ın Dünü, Bugünü ve Yarını: Lojistik Sektörü”. International Regional Development Conference, Munzur University, Tunceli. Eylül 21-23, 2017.

Kirch Martin, Olaf Poenicke and Klaus Richter. "RFID in Logistics and Production - Applications. Research ve Visions for Smart Logistics Zones”. Procedia Engineering. 178 (2017): 526-53.

Mangan, John, Chandra Lalwani ve Tim Butcher. Global Logistics and Supply Chain Management. West Sussex, England: John Wiley\&Sons. Chichester. 2008.

Morgan, David ve Robert Morgan. Single-Case Research Methods For The Behavioral and Health Sciences. SAGE Publications. 2008.

Oleśków-Szłapka, Joanna ve Piotr Lubińsk. "New Technology Trends and Solutions in Logistics and Their Impact on Processes". 3rd International Conference on Social Science. Shanghai, China. December 9-11, 2016.

Öztürk, Gürkan, Ali Özkazanç ve Oğuzhan Kalabak. Lojistikte Teknoloji Kullanımı. Editör, Gürkan Öztürk. Anadolu Üniversitesi Yayın No: 2155. Açıöğretim Fakültesi Yayın No: 1183. Eskişehir, 2013.

Podaril, Martin ve Soňa Rusnakova. “Trends and Development In Logistics”. LOGI Scientific Journal on Transport and Logistics. 5/2 (2014): 50-55.

Rennung, Frank, Caius Tudor Luminosua ve Anca Draghici. "Service Provision in the Framework of Industry 4.0". Procedia - Social and Behavioral Sciences. 221 (2016): 372-377. 
Sauvage, Thierry. "The Relationship Between Technology and Logistics Third-Party Provider"s. International Journal of Physical Distribution \& Logistics Management. 33/3(2003): 236-253.

Stock Tim ve Guenther Seliger. "Opportunities of Sustainable Manufacturing in Industry 4.0”. Procedia CIRP. 40 (2016):536-541.

Strandhagen, Jan Ola, Logan Reed Vallandingham, Giuseppe Fragapane, Jo Wessel Strandhagen, Aili Biriita Hætta Stangeland ve Nakul Sharma. "Logistics 4.0 and Emerging Sustainable Business Models". Advances in Manufacturing. 5 (2017): 359-369.

Szymańska Olga, Michał Adamczak ve Piotr Cyplik Cyplik. "Logistics 4.0 - A New Paradigmor Set of Known Solutions?", Research in Logistics and Production, 7/4. (2017): s. 299-310.

Tekin, Hasan Hüseyin. "Nitel Araştırma Yönteminin Bir Veri Toplama Tekniği Olarak Derinlemesine Görüşme”. İstanbul Üniversitesi Sosyoloji Dergisi. 13/3 (2006): 101-116.

Tjahjono, Benny, C. Esplugues, Ares Enrique ve G. Pelaez. "What does Industry 4.0 Mean to Supply Chain?". Manufacturing Engineering Society International Conference. Vigo (Pontevedra), Spain. June 28-30, 2017.

Uckelmann Dieter. “A Definition Approach to Smart Logistics", https://rusmart.e-werest.org/2008/uckelmann.pdf, Erişim Tarihi: 02.04.2018.

Witkowski, Krzysztof. "Internet of Things, Big Data, Industry 4.0 - Innovative Solutions in Logistics and Supply Chains Management". Procedia Engineering. (2017): 763-769.

Zelewski, Stephan, Alessa Münchow-Küster ve Rene Föhring. "Logistics Trends 2020: A National Delphi Study Concerning the German Logistics Sector". Next Generation Supply Chains Trends and Opportunities. (Kersten, W., Blecker, T., Ringle, C. M., eds.) HICL, Hamburg. (2014): 69-85. 
İNSAN\&İNSAN, Y11/Year 7, Sayı/Issue 23, Kış/Winter 2020, 37-51

DOI: https://doi.org/10.29224/insanveinsan.513453

\section{Logistics 4.0 Applications and Industry 4.0 from Logistics Firms' Point of View}

BİHTER KARAGÖZ / HANDE BEGÜM BUMIN DOYDUK

Abstract: Businesses operating in logistics, one of the technology intensive sectors, use many different technologies to survive and gain competitive advantage. Logistics 4.0 applications for today's competitive products and services are rapidly changing the way businesses do business. In this study, the point of view of the businesses offering logistics services in Turkey towards 4.0 work logistics and their application levels have been analyzed. For this purpose, in-depth interviews with ten different logistics service providers were reached and logistics 4.0 concept and its applications were asked. The effects of these applications on was tried to be determined. From this, a SWOT (Strengths, Weaknesses, Opportunities, Threats) analysis of logistics 4.0 applications for the sector was made. Whether businesses have logistics practice or not, they understand the importance of these practice. The result of the study demonstrates that logistics 4.0 practices will become increasingly important for our country.

Keywords: Industry 4.0, Logistics 4.0, Logistics. 